\title{
Genetic counselling, confidentiality, and the medical interests of relatives
}

\author{
Raanan Gillon Imperial College and King's College, London University
}

Following the World Medical Association's brief declaration on genetic counselling and genetic engineering (1), Dr Richard West offers in this issue of the journal a resumé of areas of contemporary professional agreement about genetic counselling, at least so far as those health carers who accept the moral permissibility of abortion are concerned.

Thus the fundamental objectives of genetic counselling are seen to be the provision of information to those who are, or whose relatives are or will be, at risk of significant genetic or congenital disease, including information about such options as are available to reduce or eliminate such risks.

The issues which turn clearly on attitudes to abortion are not addressed - as Dr West says, the arguments have been well rehearsed. However, doctors are urged not to impose their own moral attitudes upon their patients and if they find themselves disagreeing with the moral stance of their patients over these issues they should explain their situation and advise the patient to consult a clinical geneticist. Such views are now sufficiently common within the medical profession, even among those members who strongly disapprove of abortion, to be properly described as consensus views.

Less agreement may be expected over Dr West's assertion that 'the doctor is entitled to limited breach of confidentiality to a third party where it is in the medical interest of that third party to know genetic information'; the underlying issues deserve some consideration.

The norms of medical confidentiality require doctors not to divulge information imparted to them by their patients which those patients wish to keep secret. Such medical confidentiality has been an obligation in medical practice at least since Hippocratic times and can be justified from a variety of moral standpoints - as a value in itself within the class of promise keeping, and/or within the class of respect for privacy; and/or as a manifestation of respect for autonomy; or simply as a value which conduces to the utilitarian ideal of welfare maximisation (2). However, despite stalwart defences to the contrary (3) there seem to be no convincing moral defenses for an absolute principle of medical confidentiality according to which confidences must in no circumstances be breached, no matter how harmful the consequences of maintaining confidentiality would $\stackrel{\Phi}{\Phi}$ be. Rather, the principle of medical confidentiality $\vec{f}$ seems most firmly justifiable as a very strong prima ${ }_{.}$ facie principle, to be overridden only by even stronger moral claims.

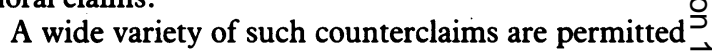
as valid defences for breach of confidentiality by the $\vec{\square}$ General Medical Council (GMC) in Britain (4) and ${ }_{\varnothing}^{\Phi}$ somewhat fewer by the British Medical Association $\frac{\Phi}{3}$ (BMA) (5) - but neither organisation explicitly permits the medical interests of third parties to justify breach of ${ }^{\stackrel{\Phi}{-}}$ medical confidentiality. However, perhaps the $\overrightarrow{0}$ exceptions offered by the GMC and BMA do implicin encompass the medical interests of third parties as being sufficient justification of breach off confidentiality? Seven of the eight proferred exceptions are clearly inapplicable. Thus by hypothesis the exception of patient consent does not apply and the transfer of information to other health care workers is not the relevant issue; the exception $\frac{0}{3}$ whereby doctors are permitted to inform relatives or close friends where it is medically undesirable to seek the patient's consent is clearly not relevant; nor is the exception of disclosure to a third party, other than a relative, in 'the best interests of the patient'; the $-\sigma$ exceptions based on statutory requirements to disclose 3 . and court directives to disclose do not apply, and nor does the dispensation to disclose medical information? for the purpose of approved medical research. Only theo remaining exception - overriding of confidentiality 'in? the public interest' - seems to offer the possibility ofo support. However, as that exception stands at present it seems unlikely to encompass the medical interests of others, unless harm equivalent to 'grave or very serious $N$ crime' is caused or allowed to go unpunished by failure స్ల to disclose a medical confidence. Thus the possiblyo relevant GMC exception states: 'Rarely, disclosure may be justified on the ground that it is in the public interest which, in certain circumstances such as, for example, investigation by the police of a grave or very serious crime, might override the doctor's duty to ${ }^{-}$ maintain his patient's confidence' (4). Similarly the $\vec{\Phi}$ BMA exception of 'the doctor's overriding duty to society' is also glossed in terms of 'a very grave crime where the security of the public is at risk' (5). 
Is disclosure of genetic information to other members of a patient's family, when the patient has refused to permit such disclosure and rejects the doctor's requests to pass on information given in medical confidence, justifiable under this exception as being 'in the public interest'? And if it is, is other information, apart from genetic information, disclosed in confidence by a patient also justifiably to be passed on to other members of the patient's family against the patient's will, provided that such disclosure is thought by the doctor to be in the third party's medical interests? And if so, why restrict such disclosure to family members? Presumably all third parties should then be entitled to be given confidential medical information if it is in their medical interests to have it? Thus the proposed exception to confidentiality of third party medical benefit would, for example, equally justify doctors breaking confidences and passing information about sexually transmitted disease on to sexual partners.

Such questions are not rhetorical, and arguments can be offered in support of disclosure - for example arguments based on the claim that doctors have a wideranging duty to all whose health is threatened to try to benefit them medically and to try to prevent or at least minimise their risk of being harmed by disease. Along such lines many will argue that if a doctor in the course of a consultation discovers that others are substantially threatened, whether by illness or anything else, then that doctor should ensure that the necessary steps are taken to minimise the threat, whether or not the patient gives permission. Similarly it could be argued that in some cases failure to inform about risks of severe genetic disease would result in sufficiently substantial harm to others to justify such overriding of a patient's confidences.

On the other hand with every additional erosion of medical confidentiality in the interests of others the principle itself becomes ever more suspect, more 'decrepit' in Siegler's memorable phraseology (6), and presumably the medical profession becomes ever less trusted to keep its patients' secrets. Such reduction in trust is increasingly likely to stop patients from passing on any information to doctors which they wish to keep secret. As a result the general provision of good quality medical care is likely to suffer, to the detriment of the very public interest that is cited as justification for the breaking of medical confidentiality.

At present it seems likely that the norms of medical confidentiality as expressed in official guidelines favour the latter argument, and do not permit transgression of medical confidences in order to serve the medical interests of third parties, unless harm equivalent to grave or very serious crime is involved. Whether or not information about genetic disorders would 'officially' be thought to fall into this category is not stated in the GMC and BMA codes, but it seems unlikely. A recent King's Fund consensus statement on screening for fetal and genetic abnormality was more explicit, stating that if it is desirable to include relatives and partners in screening this must also be based on informed consent' (7). However, in America the President's commission on bioethical issues argued that in limited circumstances confidentiality could justifiably be transgressed in the medical interests of relatives, where serious harm to relatives was likely to be prevented by so doing (8).

In an area of such contention and uncertainty the case proposed by Dr West requires rigorous scrutiny not only by the medical professions but also by the public in whose interests such reform is offered. Whatever the outcome, the norms of medical confidentiality adopted by the profession should surely be widely and effectively publicised, so that patients can have a reasonably clear idea of the circumstances in which information which they give their doctors in confidence may nonetheless be passed on to others against their will.

\section{References and notes}

(1) World Medical Association. Statement on genetic counselling and genetic engineering, 1987. Reprinted in: IME Bulletin 1987; 31: 8-9.

(2) Gillon R. Philosophical medical ethics. Chichester: Wiley, 1986; 106-112.

(3) Kottow M. Medical confidentiality: an intransigent and absolute obligation. Fournal of medical ethics 1986; 12: 117-122.

(4) General Medical Council. Professional conduct and discipline: fitness to practise. London: GMC, 1987: 19-22.

(5) British Medical Association. The Handbook of Medical Ethics. London, 1984; 12-15.

(6) Seigler $M$. Confidentiality in medicine: a decrepit concept. New England journal of medicine 1982; 307: 1518-1521.

(7) King's Fund forum consensus statement: screening for fetal and genetic abnormality. British medical journal 1987; 295: 1551-1553.

(8) President's commission for the study of ethical problems in medicine. Screening and counseling for genetic conditions. Washington DC: US Government Printing Office, 1983: 42-45. 